\title{
Optimal Decision of Different Fair Reference Points in Supply Chain under "Farmer-Supermarket Direct-Purchase" Mode
}

\author{
Yanhong Qin, Hong Le \\ School of Management, Chongqing University of Technology, Chongqing, China \\ Email: qinyanhong24@163.com
}

How to cite this paper: Qin, Y.H. and Le, H. (2019) Optimal Decision of Different Fair Reference Points in Supply Chain under "Farmer-Supermarket Direct-Purchase" Mode. Open Access Library Journal, 6: e5457.

https://doi.org/10.4236/oalib.1105457

Received: May 8, 2019

Accepted: May 21, 2019

Published: May 24, 2019

Copyright $\odot 2019$ by author(s) and Open Access Library Inc.

This work is licensed under the Creative Commons Attribution International License (CC BY 4.0).

http://creativecommons.org/licenses/by/4.0/

\begin{abstract}
In a two-echelon "Farmer-Supermarket Direct-Purchase" supply chain composed of a supermarket and a farmer, the dominant supermarket used the Nash equilibrium solution and the Shapley value as the fair reference points. By constructing the Stackelberg game model, this paper analyzed the influence of supermarket's fairness preference on the operation of supply chains and made a sensitivity analysis. The research indicates that supermarket's fairness preference decreases order prices and the effort level of farmer increases the utility of the supermarket but reduces the income of the farmer. No matter whether the Nash equilibrium solution or the Shapley value is used as the fair reference point of the supermarket, the supply chain cannot be achieved coordination. However, the supply chain can be improved with the Shapley value as the fair reference point. Thus, the farmer, the supermarket and the supply chain tend to use Shapley value as a fairness reference point for the supermarket.
\end{abstract}

\section{Subject Areas \\ Supply Chain Management}

\section{Keywords}

Fair Reference Point, The Shapley Value, The Nash Equilibrium Solution, Farmer-Supermarket Direct-Purchase

\section{Introduction}

The issue of agriculture is one of the core issues of economic development. The Ministry of Agriculture encourages innovation in the circulation of agricultural 
products and actively promotes the direct connection between large supermarkets and farmers. At present, scholars at home and abroad have conducted extensive research on "Farmer-Supermarket Direct-Purchase" supply chain, which shows that it can reduce redundant links in circulation and improve the circulation efficiency of agricultural products [1] [2] [3]. Therefore, the new agricultural product supply chain mode of "Farmer-Supermarket Direct-Purchase" is an effective way to solve the problem of agriculture.

However, in the "Farmer-Supermarket Direct-Purchase" supply chain, Yang [3] shows that supermarkets need to bear higher operating costs and taxes, which leads to further increase of the operational risk and repayment cycle. Therefore, supermarkets believe that they should get more profits from the supply chain in order to achieve fairness. When supermarkets seek more profits, they will use their positional advantages to lower the order prices of agricultural products in order to achieve fair returns consistent with their own contributions, but at the same time, they will frustrate the production enthusiasm of farmers causing frequent incidents of agricultural product quality problems. For example, there were seven farmers in order to make the bean sprouts grow rapidly in Zhejiang. In the process of bean sprout production, the additives prohibited by the state were incorporated, and more than 150 tons of poisonous bean sprouts were sold in just a few years (People's Network, 2018).

At the same time, a large number of behavioral economics studies show that decision makers often have fair preference behavior. Cui et al. [4] introduced fair preference into supply chain for the first time, and studied the coordination of supply chain under deterministic demand. The results show that simple wholesale price contract under fair preference can achieve supply chain coordination. Katok et al. [5] show that decision-makers tend not to pay attention to favorable inequities, but are more sensitive to unfavorable inequities. Qin et al. [6] studied the influence of decision makers on the supply chain by considering the symmetry and asymmetry of fairness preference information when only concerned about unfairness. The decision-maker determines whether the self-return is fair or not depends on its psychological expected income, that is, the fair reference point. When it is below the fair reference point, the decision-maker produces fair negative utility, so the fair preference performance of the decision-maker often depends on the fair reference point chosen by himself. Most of the existing studies use absolute fairness as a fair reference point, that is, directly compare with the other party's income, such as Cui et al. [4], Caliskan [7]. In reality, the strength and contribution of all parties in the supply chain will affect the fairness of benefit distribution, that is, fairness has relativity, so scholars gradually begin to pay attention to the relative fair reference point. Considering the bargaining power of all parties and their different positions in the supply chain, a few scholars have studied Nash equilibrium solution as a fair reference point [8] [9]. The Nash equilibrium solution is the result of non-cooperative game, that is, decision-makers make decisions to maximize their own profits under the influence 
of mutual interests, which mainly depends on the bargaining power of all parties. Considering the different contributions of every party in the supply chain, some scholars have studied Shapley value as a fair reference point [10] [11]. The Shapley value is the result of cooperative game, that is, the decision-maker makes the decision of income distribution when he reaches cooperation, considering the difference in the ability and contribution of every party, which has certain rationality and practical application. Currently, the Nash equilibrium solution and the Shapley value are the most representative values of relative fair reference points. Previous studies have compared the absolute fairness of reference points with the Nash equilibrium solutions in relative fairness [12]. However, the comparison between the Nash equilibrium solution and the Shapley value in the relative fair reference point is still scarce.

Facing the frequent quality and safety issues of agricultural products, more and more studies have been done to take fair preference into account in the operation of agricultural supply chain in order to alleviate the unfair distribution of income in agricultural supply chain, promote the operation of agricultural supply chain and improve the quality of agricultural products. For example, Yao and $\mathrm{Pu}$ [13] studied the impacts of farmers' fairness and quality improvement on supply chain equilibrium strategy under the background of agricultural supermarket docking; Sun et al. [14] found that suppliers' fairness and quality of agricultural products affected the establishment of agricultural supply chain relationship through the survey of 450 agricultural products suppliers. However, most literatures consider the impacts of farmers' fair preference on supply chain. Only a few scholars pay attention to the impacts of supermarkets' fair preference on the operation of agricultural supply chain. For example, Feng et al. [15] showed that when the retailer has unfair aversion, it will lower the order price of agricultural products, but the channel coordination status remains unchanged. Zhang X. and Zhang Q. [16] considered the fair concern behavior of the retailer. The research showed that the retailer's order quantity and freshness efforts will increase as the suppliers share the cost of retailers. On the one hand, supermarkets have gained more profits in the agricultural supply chain operation, but on the other hand, supermarkets constantly depress the ordering price of agricultural products, frustrate farmers' enthusiasm for production and lead to frequent problems in the quality and safety of agricultural products. In the final analysis, it is because the fair reference points considered by supermarkets affect their decision-making and the operation of agricultural supply chain. Therefore, it is necessary to study the impact of decision makers' relative fair reference points on the operation of agricultural supply chains.

Based on this, this paper will try to study in the following two aspects: 1) consider the supermarket's fairness in "Farmer-Supermarket Direct-Purchase" supply chain; 2) study the impact of the supply chain operation with the Nash equilibrium solution and the Shapley value as fair reference points respectively. Therefore, this paper will use the Nash equilibrium solution and the Shapley 
value as the fair reference point respectively under "Farmer-Supermarket Direct-Purchase" supply chain and analyze the impact of the supermarket's fairness on decision-making such as ordering price and farmer's effort level.

\section{Model Formulation and Assumptions}

Under "Farmer-Supermarket Direct-Purchase" supply chain, this paper studies the secondary agricultural product supply chain composed of single farmer and single supermarket, in which the supermarket is the leader and farmer is the follower. The marginal cost of the farmer is consistent with the level of effort [17], that is, the higher the level of effort of the farmer, the more time and money the farmer invests in agricultural products. Before the arrival of the sales season, the farmer decides his own effort level according to the order price set by the supermarket, so a Stackelberg game is formed between the farmer and the supermarket. The game process is as follows: firstly, the supermarket as the leader formulates the order price of agricultural products; secondly, the farmer decides his own effort level according to the order price. The specific assumptions of this paper are as follows:

Assumption 1 The market demand for agricultural products is $d=y\left(p, e_{s}\right) \cdot \varepsilon$. Among them, $y\left(p, e_{s}\right)=\eta p^{-a} e_{s}^{b}, \eta$ is the market demand base $(\eta>0), a$ is the demand price elasticity coefficient $(a>0), b$ is the effort level elasticity coefficient $(0<b<1), p$ is the retail price $\left(p>w>e_{s}>0\right), \varepsilon$ is the random demand factor and obeys the uniform distribution between $[0,1]$. Because the market demand of agricultural products is not only negatively correlated with the selling price $p$, and positively correlated with the farmer's effort level $e_{s}$, but also affected by random factors $\varepsilon$ (such as weather, festivals, etc.) [12].

Assumption 2 The order quantity of the supermarket is $Q=\alpha y\left(p, e_{s}\right)=\alpha \eta p^{-a} e_{s}^{b} \quad(\alpha \in(0,1))$. Among them, $\alpha$ is the impact of random demand $\varepsilon$ on the supermarket's order quantity.

Assumption $3 \lambda_{r}$ is the supermarket's fair coefficient $\left(\lambda_{r}>0\right)$. The higher the value of $\lambda_{r}$, the stronger the fairness intensity of the supermarket, and the greater the impact of the negative utility generated by the lower self-income than the fair reference point.

Assumption $4 \pi_{s}, \pi_{r}$ and $\pi_{s c}$ respectively express the profits of the farmer, the supermarket and the supply chain; $u_{s}, u_{r}$ and $u_{s c}$ respectively indicate the utility of the farmer, the supermarket, the supply chain; $\bar{\pi}_{r}^{N a}$ and $\bar{\pi}_{r}^{S P}$ respectively represent the Nash equilibrium solution and the Shapley value of the supermarket.

Assumption 5 The information between the farmer and the supermarket is completely symmetrical, and the risks on both sides are neutral. The residual value and shortage loss of surplus agricultural products in the supermarket are all zero.

Assumption 6 The superscripts " $c$ ", " $b$ ", " $N a^{*}$ ” and " $S P^{*}$ ” respectively in- 
dicate the optimal decision-making of centralized decision, the supermarket as fair neutral, the supermarket using the Nash equilibrium solution and the Shapley value as the fair reference point.

\section{Model Construction and Analysis}

\subsection{Modeling and Analysis of the Supermarket as Fair Neutral}

When the supermarket is fair neutral, both the farmer and the supermarket aim to pursue their own maximum profits. The profit function of the farmer, the supermarket and the supply chain are as follows:

$$
\begin{gathered}
\pi_{s}=\left(w-e_{s}\right) \alpha \eta p^{-a} e_{s}^{b} \\
\pi_{r}=p E\{\min [Q, d]\}-w Q \\
=\int_{0}^{\alpha}(p d-w Q) d_{\varepsilon}+\int_{\alpha}^{1}(p Q-w Q) d_{\varepsilon} \\
=(p-w) \alpha \eta p^{-a} e_{s}^{b}-\frac{\alpha^{2} \eta p^{1-a} e_{s}^{b}}{2} \\
\pi_{s c}=\left(p-e_{s}\right) \alpha \eta p^{-a} e_{s}^{b}-\frac{\alpha^{2} \eta p^{1-a} e_{s}^{b}}{2}
\end{gathered}
$$

\subsubsection{Centralized Decision}

Under centralized decision-making, the optimal situation is when the total profit of the supply chain reaches its maximum. The objective function of the decision is $\max _{e_{s}^{c}} \pi_{s c}=\left(p-e_{s}\right) \alpha \eta p^{-a} e_{s}^{b}-\frac{\alpha^{2} \eta p^{1-a} e_{s}^{b}}{2}$.

Through derivation, $\frac{\mathrm{d}^{2} \pi_{s c}}{\mathrm{~d} e_{s}^{2}}=-\frac{b \alpha \eta e_{s}^{b}\left[p(2-\alpha)(1-b)+2 e_{s}(b+1)\right]}{2 p^{a} e_{s}^{2}}<0$, $\frac{\mathrm{d} \pi_{s c}}{\mathrm{~d} e_{s}}=0$, then the farmer's best effort level is $e_{s}^{c}=\frac{b p(2-\alpha)}{2(b+1)}$. At this time, by substituting the best effort level of the farmer $e_{s}^{c}$ into Equation (3), the maximum total profit of the supply chain is: $\pi_{s c}^{c}=\frac{\eta \alpha(2-\alpha) p^{1-a}}{2(b+1)}\left(\frac{b p(2-\alpha)}{2(b+1)}\right)^{b}$.

\subsubsection{Decentralized Decision}

Under decentralized decision-making, the decision-making problem $P_{1}$ of the farmer and the supermarket forms a Stackelberg game, which can be expressed as:

$$
\begin{aligned}
& P_{1}: \max _{w} \pi_{r}=(p-w) \alpha \eta p^{-a} e_{s}^{b}-\frac{\alpha^{2} \eta p^{1-a} e_{s}^{b}}{2} \\
& \text { s.t. } e_{s}^{b}\left(w^{b}\right) \in \arg \max \pi_{s}^{b} \\
& e_{s}^{b}<w^{b}
\end{aligned}
$$

By using the reverse induction method, the optimal strategies for the farmer and the supermarket can be obtained as follows: $e_{s}^{b^{*}}=\frac{b^{2} p(2-\alpha)}{2(b+1)^{2}}$, 
$w^{b^{*}}=\frac{b p(2-\alpha)}{2 b+2}$.

At this point, the supermarket's optimal order price $w^{b^{*}}$ and the farmer's best effort level $e_{s}^{b^{*}}$ are substituted into Equation (1), (2), and (3). The profit of the farmer is: $\pi_{s}^{b^{*}}=\frac{(2-\alpha) \eta \alpha b p^{1-a}}{2(b+1)^{2}}\left(\frac{b^{2} p(2-\alpha)}{2(b+1)^{2}}\right)^{b}$, the profit of the supermarket is: $\pi_{r}^{b^{*}}=\frac{(2-\alpha) \eta \alpha p^{1-a}}{2(b+1)}\left(\frac{b^{2} p(2-\alpha)}{2(b+1)^{2}}\right)^{b}$, and the profit of supply chain is $\pi_{s c}^{b^{*}}=\frac{(2-\alpha)(2 b+1) \eta \alpha p^{1-a}}{2(b+1)^{2}}\left(\frac{b^{2} p(2-\alpha)}{2(b+1)^{2}}\right)^{b}$.

\subsection{Model Construction and Analysis of Supermarket Using the Nash Equilibrium Solution as Fair Reference Point}

When the supermarket uses the Nash equilibrium solution as a fair reference point, the supermarket will produce certain positive and negative effects by comparing his own profit with the Nash equilibrium solution. Therefore, the supermarket aims at maximizing his own utility while the farmer still aims at maximizing his own profit.

According to the Nash bargaining model algorithm [9], the Nash equilibrium solution of the supermarket can be obtained as $\bar{\pi}_{r}^{N a}=\frac{1+\lambda_{r}}{2+\lambda_{r}} \pi_{s c}$. At this time, the utility functions of the farmer, the supermarket and the supply chain are as follows:

$$
\begin{gathered}
u_{s}^{N a}=\pi_{s} \\
u_{r}^{N a}=\pi_{r}-\lambda_{r}\left(\bar{\pi}_{r}^{N a}-\pi_{r}\right) \\
u_{s c}^{N a}=u_{s}^{N a}+u_{r}^{N a}
\end{gathered}
$$

In this case, the decision-making problem $P_{2}$ between the supermarket and the farmer still constitutes a Stackelberg game, which can be expressed as:

$$
\begin{aligned}
& P_{2}: \max _{w} u_{s}^{N a}=\pi_{r}-\lambda_{r}\left(\bar{\pi}_{r}^{N a}-\pi_{r}\right) \\
& \text { s.t. } e_{s}^{N a}\left(w^{N a}\right) \in \arg \max u_{s}^{N a} \\
& e_{s}^{N a}<w^{N a}
\end{aligned}
$$

By using the reverse induction method, the optimal strategies of the farmer and the supermarket can be obtained: $e_{s}^{N a^{*}}=\frac{b^{2} p(2-\alpha)}{\left(2 b+2+\lambda_{r}\right)(1+b)}$, $w^{N a^{*}}=\frac{b p(2-\alpha)}{2 b+2+\lambda_{r}}$.

At this time, the supermarket's optimal order price $w^{N a^{*}}$ and the farmer's best effort level $e_{s}^{N a^{*}}$ can be substituted into Equation (4), (5), and (6). The utility of the farmer is $u_{s}^{N a^{*}}=\frac{(2-\alpha) \eta \alpha b p^{1-a}}{\left(2 b+2+\lambda_{r}\right)(1+b)}\left(\frac{b^{2} p(2-\alpha)}{\left(2 b+2+\lambda_{r}\right)(1+b)}\right)^{b}$, the utility 
of the supermarket is $u_{r}^{N a^{*}}=\frac{(2-\alpha)\left(1+\lambda_{r}\right) \eta \alpha p^{1-a}}{\left(2+\lambda_{r}\right)(1+b)}\left(\frac{b^{2} p(2-\alpha)}{\left(2 b+2+\lambda_{r}\right)(1+b)}\right)^{b}$, and the utility of the supply chain is

$u_{s c}^{N a^{*}}=\frac{\left(\lambda_{r}{ }^{2}+3 b \lambda_{r}+3 \lambda_{r}+4 b+2\right)(2-\alpha) \eta \alpha p^{1-a}}{\left(2 b+2+\lambda_{r}\right)\left(2+\lambda_{r}\right)(1+b)}\left(\frac{b^{2} p(2-\alpha)}{\left(2 b+2+\lambda_{r}\right)(1+b)}\right)^{b}$.

Proposition 1 Compared with the optimal value of decision-making under fair neutrality of the supermarket, when the supermarket uses the Nash equilibrium value as the fair reference point,

1) the farmer's best effort level and the supermarket's optimal order price will decrease.

2) the utility of the supermarket will increase, while the utility of the farmer and the utility of the supply chain will decrease.

Proof: Through $e_{s}^{N a^{*}}-e_{s}^{*}=-\frac{b^{2} p \lambda_{r}(2-\alpha)}{\left(2 b+2+\lambda_{r}\right)(1+b)^{2}}<0$, it can be seen that when the supermarket uses the Nash equilibrium solution as a fair reference point, the effort level of the farmer is lower than that of decision-making when the supermarket is fair neutral. Similarly, by comparing the difference, it can be concluded that the order price of the supermarket decreases, the utility of supermarket increases, and the utility of the farmer and the supply chain decreases.

According to Proposition 1, under "Farmer-Supermarket Direct-Purchase" supply chain, when the supermarket uses the Nash equilibrium value as a fair reference point, it means that the supermarket pays more attention to his contribution to the supply chain and will compare his own income with the Nash equilibrium solution resulting in a negative effect. Once the supermarket feels that his income has failed to reach the fair reference point, the supermarket will punish the farmer by lowering the order price in order to get more utility. When the supermarket lowers the order price, it will inevitably lead to a decrease in the utility of the farmer. As a disadvantaged party, the farmer has no ability to bargain with the supermarket to increase the order price, so he will naturally reduce his own losses by reducing production costs. At this time, the farmer will reduce his own efforts to shorten the cultivation cycle of agricultural products, such as reducing the management and cultivation of agricultural products, extreme use of growth hormone and so on. For the supply chain, the increase of the supermarket's utility is at the expense of the farmer's utility, so the supply chain utility will also be reduced.

Proposition 2 When the supermarket uses the Nash equilibrium solution as a fair reference point, the supermarket's order price, the farmer's effort level, the farmer's and the supply chain's utility decrease with the increase of the supermarket's fairness intensity.

Proof: $\frac{\mathrm{d} w^{N a^{*}}}{\mathrm{~d} \lambda_{r}}=-\frac{b p(2-\alpha)}{\left(2 b+2+\lambda_{r}\right)}<0$ shows that when the fairness preference of the supermarket increases, the order price of the supermarket decreases. Simi- 
larly, Proposition 2 can be obtained by deriving the fairness coefficients of the farmer's effort level, the farmer's utility, the supermarket's utility and the supply chain's utility.

Proposition 1 shows that when the supermarket uses the Nash equilibrium solution as a fair reference point, it will lead to the reduction of the farmer's effort level, the supermarket's order price, the farmer's utility and the supply chain's utility. Therefore, with the increase of the supermarket's fairness intensity, this phenomenon will inevitably be aggravated, that is, the supermarket's order price, the farmer's effort level, the farmer's and the supply chain's utility will decrease with the increase of the supermarket's fair preference intensity.

Proposition 3 If the supermarket uses the Nash equilibrium solution as the fair reference point, when $0<\lambda_{r}<\frac{-3 b+1+\sqrt{9 b^{2}+2 b+1}}{2 b}$, the utility of the supermarket increases with the increase of fair preference intensity; on the contrary, the utility of the supermarket decreases with the increase of fair preference intensity.

Proof: when $0<\lambda_{r}<\frac{-3 b+1+\sqrt{9 b^{2}+2 b+1}}{2 b}, \frac{\mathrm{d} u_{r}^{N a^{*}}}{\mathrm{~d} \lambda_{r}}>0$, i.e. the utility of the supermarket increases with the increase of his own fairness intensity. When $\lambda_{r}>\frac{-3 b+1+\sqrt{9 b^{2}+2 b+1}}{2 b}, \frac{\mathrm{d} u_{r}^{N a^{*}}}{\mathrm{~d} \lambda_{r}}<0$, i.e. the utility of the supermarket decreases with the increase of his own fair intensity.

According to Proposition 3, if the supermarket uses the Nash equilibrium solution as a fair reference point, the supermarket's own fairness preference strength exceeds a certain threshold, which will lead to a decline in its own utility. This is because $w^{N a^{*}}<w^{b^{*}}$, that is to say, when the supermarket uses the Nash equilibrium solution as the fair reference point, the lowest order price will inevitably lead to the lowest effort level of the farmer at this time $\left(e_{s}^{N a^{*}}<e_{s}^{b^{*}}<e_{s}^{c}\right)$. Moreover, it is known from Proposition 2 that the supermarket order price and the farmer's effort level decrease with the increase of the supermarket fairness intensity. When the level of the farmer's effort is low to a certain extent, various problems of agricultural product quality will emerge in endlessly, such as adding growth hormone, filling in rotten or abandoning planting, etc., which will damage the supermarket reputation and affect supermarket sales. That is to say, the utility of the supermarket begins to decrease with the increase of his fair preference intensity. Therefore, the supermarket should reasonably control his own fairness intensity. By signing a protection price acquisition contract in advance, it can restrain the supermarket's behavior of lowering the order price regardless of consequences. Otherwise, it will lead to the decline of his own utility after seriously damaging the enthusiasm of the farmer.

\subsection{Model Construction and Analysis of Supermarket with Shapley Value as Fair Reference Point}

When the supermarket uses the Shapley value as a fair reference point and the 
farmer is fair neutral, the supermarket will produce certain positive and negative effects by comparing his own profit with the Shapley value. Therefore, the supermarket aims at maximizing his own utility while the farmer still aims at maximizing his own profit.

According to the Shapley value algorithm [10], the Shapley value of the supermarket is $\bar{\pi}_{r}^{S P}=\frac{\pi_{s c}}{2}$. At this time, the utility functions of the farmer, the supermarket and the supply chain are as follows:

$$
\begin{gathered}
u_{s}^{S P}=\pi_{s} \\
u_{r}^{S P}=\pi_{r}-\lambda_{r}\left(\bar{\pi}_{r}^{S P}-\pi_{r}\right) \\
u_{s c}=u_{s}^{S P}+u_{r}^{S P}
\end{gathered}
$$

In this case, the decision-making problem $P_{3}$ between the supermarket and the farmer still constitutes the Stackelberg game, which can be expressed as:

$$
\begin{aligned}
& P_{3}: \max _{w} u_{r}^{S P}=\pi_{r}-\lambda_{r}\left(\bar{\pi}_{r}^{S P}-\pi_{r}\right) \\
& \text { s.t. } e_{s}^{S P}\left(w^{S P}\right) \in \arg \max u_{s}^{S P} \\
& e_{s}^{S P}<w^{S P}
\end{aligned}
$$

By using the reverse induction method, the optimal strategies of the farmer and the supermarket can be solved: $e_{s}^{S P^{*}}=\frac{b^{2} p\left(2+\lambda_{r}\right)(2-\alpha)}{2\left(2 b+b \lambda_{r}+2 \lambda_{r}+2\right)(1+b)}$, $w^{S P^{*}}=\frac{b p\left(2+\lambda_{r}\right)(2-\alpha)}{(2 b+4) \lambda_{r}+4 b+4}$.

At this time, the supermarket's optimal order price $w^{S P^{*}}$ and the farmer's best effort level $e_{s}^{S{ }^{*}}$ are substituted into Equation (7), (8), and (9). The utility of the farmer is:

$u_{s}^{S P^{*}}=\frac{\left(2+\lambda_{r}\right)(2-\alpha) \eta \alpha b p^{1-a}}{2\left(2 b+b \lambda_{r}+2 \lambda_{r}+2\right)(1+b)}\left(\frac{b^{2} p\left(2+\lambda_{r}\right)(2-\alpha)}{2\left(2 b+b \lambda_{r}+2 \lambda_{r}+2\right)(1+b)}\right)^{b}$, the utility of the supermarket is:

$u_{r}^{S P^{*}}=\frac{\left(2+\lambda_{r}\right)(2-\alpha) \eta \alpha p^{1-a}}{4+4 b}\left(\frac{b^{2} p\left(2+\lambda_{r}\right)(2-\alpha)}{2\left(2 b+b \lambda_{r}+2 \lambda_{r}+2\right)(1+b)}\right)^{b}$, and the utility of supply chain is

$$
u_{s c}^{S P^{*}}=\frac{\left(2+\lambda_{r}\right)(2-\alpha)\left(b \lambda_{r}+4 b+2 \lambda_{r}+2\right) \eta \alpha p^{1-a}}{4\left(b \lambda_{r}+4 b+2 \lambda_{r}+2\right)(1+b)}\left(\frac{b^{2} p\left(2+\lambda_{r}\right)(2-\alpha)}{2\left(2 b+b \lambda_{r}+2 \lambda_{r}+2\right)(1+b)}\right)^{b} .
$$

Proposition 4 Compared with the optimal value of decision-making under fair neutrality of the supermarket, when the supermarket uses the Shapley value as the fair reference point,

1) the farmer's best effort level and the supermarket's order price will decrease;

2) the utility of farmer will decrease, while the utility of supermarket and the utility of supply chain will increase.

Proof: Same as proposition 1. 
Proposition 5 When the supermarket uses the Shapley value as a fair reference point, the supermarket's order price, the farmer's effort level and the farmer's utility decrease with the increase of the supermarket's fairness intensity, while the supermarket's utility and the supply chain's utility increase with the increase of supermarket's fairness intensity.

Proof: same as proposition 2.

\section{Comparative Analysis}

The decision-making under fair neutrality of supermarket is compared with the optimal decision-making of the supermarket with the Nash equilibrium solution and the Shapley value as the fair reference point.

Conclusion 1 The relationships among the indicators in different situations are as follows:

1) the order price: $w^{N a^{*}}<w^{S P^{*}}<w^{b^{*}}$

2) the effort level of the farmer: $e_{s}^{N a^{*}}<e_{s}^{S P^{*}}<e_{s}^{b^{*}}<e_{s}^{c}$

3) the utility of the farmer: $u_{s}^{N a^{*}}<u_{s}^{S P^{*}}<u_{s}^{b^{*}}$

4) the utility of the supermarket: $u_{r}^{b^{*}}<u_{r}^{N a^{*}}<u_{r}^{S P^{*}}$

5) the utility of the supply chain: $u_{s c}^{N a^{*}}<\pi_{s c}^{b^{*}}<u_{s c}^{S P^{*}}<\pi^{c}$

Conclusion 1 shows that when the supermarket has fair preference behavior, the supermarket will reduce the order price and increase his own utility from the perspective of retaliation psychology and reducing procurement costs. When the farmer knows that the supermarket has fair preference behavior, in the face of the supermarket's behavior to low the order price, the farmer will reduce the effort level in order to express dissatisfaction. Although the farmer will reduce his own costs by lowering the effort level, the change of order price of the supermarket which is dominant is larger than that of the farmer's effort, which will lead to the decrease of the farmer's utility. When the effort level of the farmer is reduced, the quality of agricultural products will decline, which will inevitably lead to the decrease of market demand for agricultural products and the decline of the supply chain's utility.

The Nash equilibrium solution of supermarket is the maximum profit decision of the supermarket by bargaining with its dominant status, and the Shapley value of the supermarket is the income distribution decision of the supermarket considering the contribution of each member in the supply chain. Therefore, the Nash equilibrium solution of the dominant supermarket must be greater than the Shapley value. When the value of fair reference point is higher, the stronger the supermarket feels unfair, the lower the order price, that is to say $w^{N a^{*}}<w^{S P^{*}}<w^{b^{*}}$. Obviously, the lower the order price, the lower the farmer's effort level and utility will be, which will lead to the decline of the supermarket's utility, namely $e_{s}^{N a^{*}}<e_{s}^{S P^{*}}<e_{s}^{b^{*}}<e_{s}^{c}, u_{s}^{N a^{*}}<u_{s}^{S P^{*}}<u_{s}^{b^{*}}$ and $u_{r}^{b^{*}}<u_{r}^{N a^{*}}<u_{r}^{S P^{*}}$.

Conclusion 2 No matter whether the Nash equilibrium solution or the Shapley value is used as the fair reference point of the supermarket, the supply chain cannot be achieved coordination. However, the supply chain can be improved 
with the Shapley value as the fair reference point.

According to conclusion 1, the relationship of the farmer's utility is $u_{s}^{N a^{*}}<u_{s}^{S P^{*}}<u_{s}^{b^{*}}$.

When the supermarket has fairness, the farmer's utility is lower than his utility with the supermarket neutrality. Therefore, no matter whether the Nash equilibrium solution or the Shapley value is used as the fair reference point of the supermarket, the supply chain cannot be achieved coordination. However, when the supermarket uses the Shapley value as the fair reference point, the supermarket's utility and the supply chain's utility are higher than their utility with the supermarket neutrality, that is $u_{r}^{b^{*}}<u_{r}^{S P^{*}}$ and $\pi_{s c}^{b^{*}}<u_{s c}^{S P^{*}}$. Therefore, the supply chain can be improved with the Shapley value as the fair reference point.

Conclusion 3 The relationship between the indicator obtained by using the Nash equilibrium solution and the Shapley value as the fair reference points and the supermarket's fair preference intensity are shown in Table 1 .

Conclusion 3 is known from proposition 2, 3 and 5.

Conclusion 4 When the supermarket has fairness preference, the farmer, the supermarket and the supply chain tend to use the Shapley value as the fair reference point.

Conclusion 4 shows that when the supermarket has fair preference, first from the perspective of the supermarket, the relationship of the supermarket's utility in conclusion 1 is $u_{r}^{N a^{*}}<u_{r}^{S P^{*}}$. It can be seen that when the Shapley value is used as the fair reference point, the supermarket's utility is the highest, so the supermarket tends to use the Shapley value as the fair reference point. Then from the perspective of the farmer, after knowing that the supermarket has fair preference behavior, the farmer's effort level relationship is $e_{s}^{N a^{*}}<e_{s}^{S P^{*}}$, and the farmer's utility relationship is $u_{s}^{N a^{*}}<u_{s}^{S P^{*}}$. For the farmer who lives on crops, it is obvious that the farmer will give priority to his own utility without stingy labor. Therefore, the farmer tends to use the Shapley value as the fair reference point. Finally, from the perspective of supply chain, the relationship of the supply chain's utility is $u_{s c}^{N a^{*}}<\pi_{s c}^{b^{*}}<u_{s c}^{S P^{*}}$. At this point, the supply chain's utility with the Shapley value as the fair reference point is not only higher than that with the Nash equilibrium solution as the fair reference point, but also better than that with supermarket fair neutrality. Hence, the supply chain tends to use the Shapley value as the fair reference point.

Table 1. Relations between the Indicators and the Fair Preference Intensity of the Supermarket.

\begin{tabular}{lcccccc}
\hline Fair reference point & $\lambda_{r}$ & $w^{*}$ & $e_{s}^{*}$ & $u_{s}^{*}$ & $u_{r}^{*}$ & $u_{s c}^{*}$ \\
\hline $\begin{array}{l}\text { The Nash } \\
\text { equilibrium } \\
\text { solution }\end{array}$ & $\uparrow$ & $\downarrow$ & $\downarrow$ & $\downarrow$ & $0<\lambda_{r}<\frac{-3 b+1+\sqrt{9 b^{2}+2 b+1}}{2 b}, \uparrow$ & $\downarrow$ \\
The Shapley value & $\uparrow$ & $\downarrow$ & $\downarrow$ & $\downarrow$ & $\lambda_{r} \geq \frac{-3 b+1+\sqrt{9 b^{2}+2 b+1}}{2 b}, \downarrow$ & $\uparrow$ \\
\hline
\end{tabular}




\section{Sensitivity Analysis}

In order to analyze more intuitively the impact of the fair preference intensity of the supermarket on the optimal order price of the supermarket, the optimal effort level of the farmer and the utility of the farmer, the supermarket and the supply chain, so this paper performs a sensitivity analysis by numerical examples.

This paper assumes that $\alpha=0.5, a=1, b=1, p=10, \eta=10, \lambda_{r} \in[0,1]$, using Maple to draw. The sensitivity analysis of the order price, the farmer's effort level, the farmer's utility, the supermarket's utility and the supply chain's utility are shown in Figures 1-5.

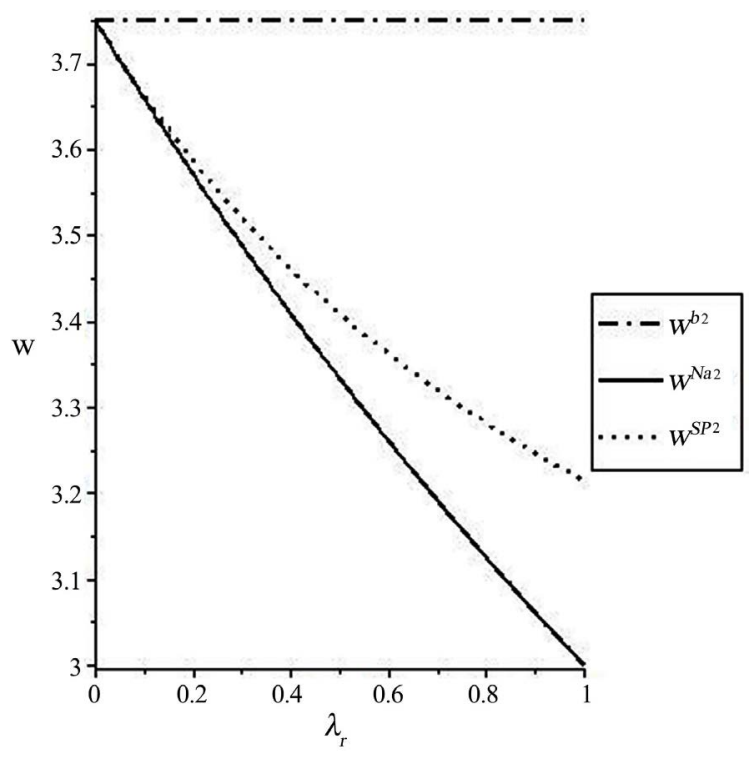

Figure 1. The Impact of $\lambda_{r}$ on the Order Price.

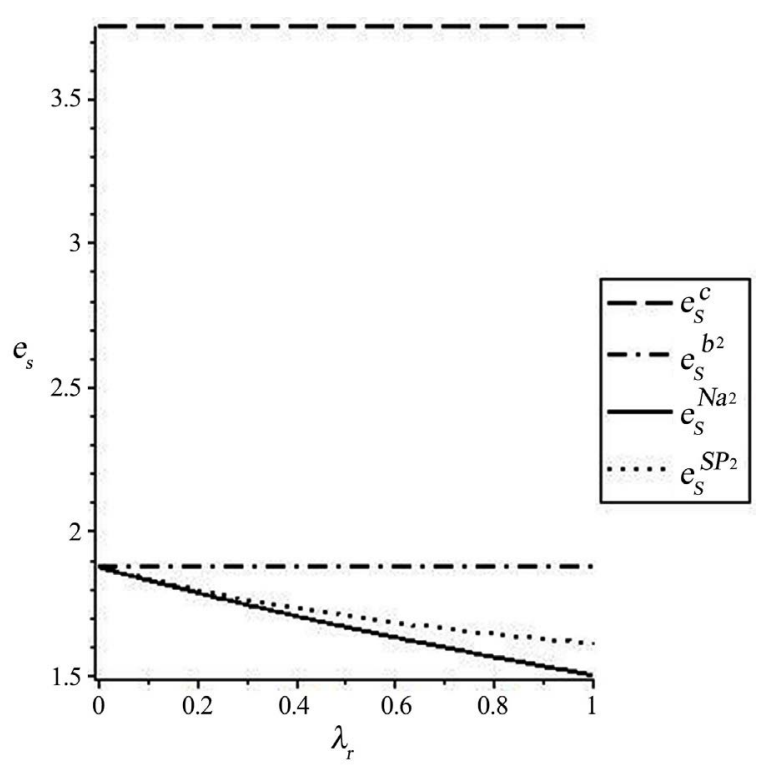

Figure 2. The Impact of $\lambda_{r}$ on the Farmer's Effort Level. 


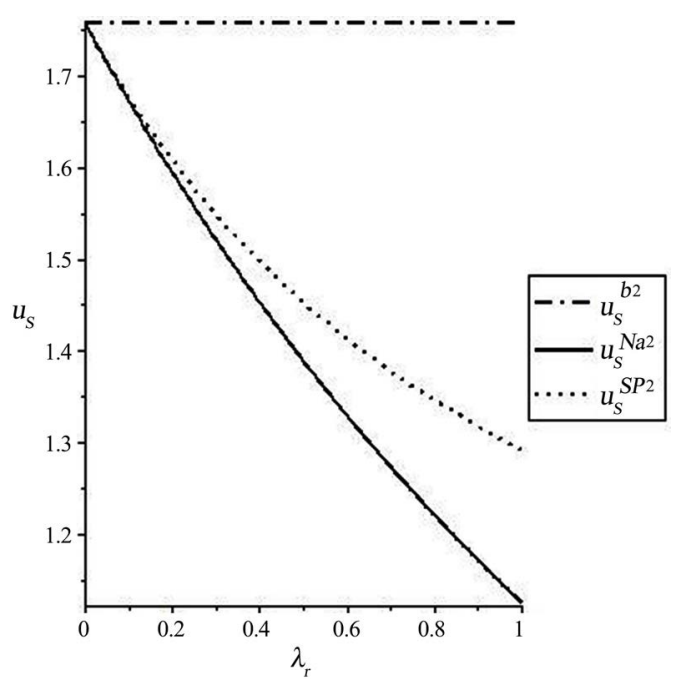

Figure 3. The Impact of $\lambda_{r}$ on the Farmer's Utility.

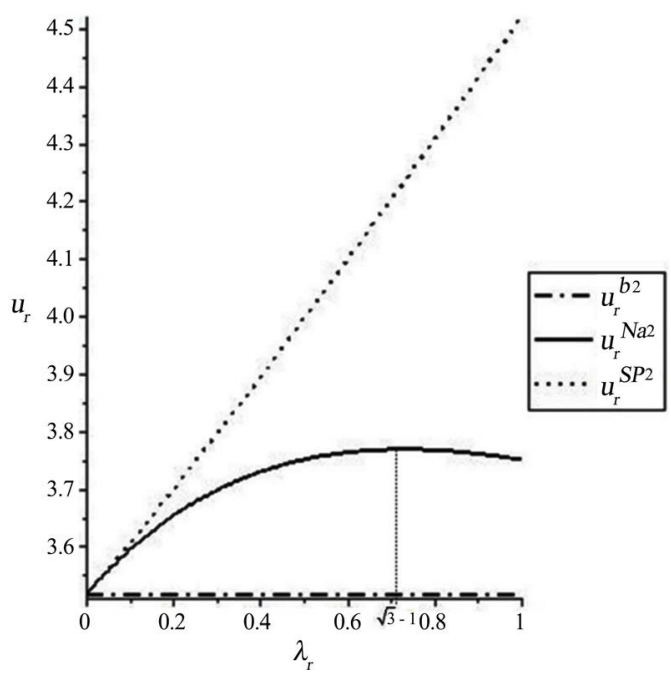

Figure 4. The Impact of $\lambda_{r}$ on the Supermarket's Utility.

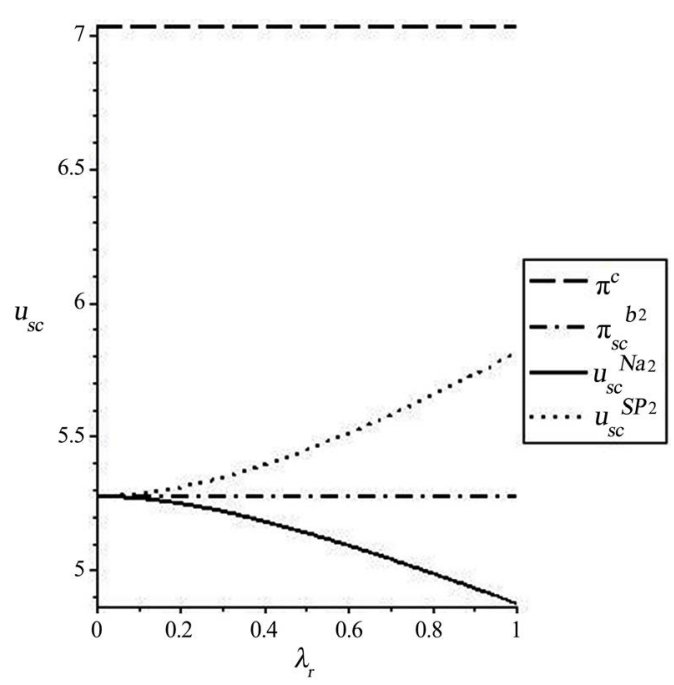

Figure 5. The Impact of $\lambda_{r}$ on Supply Chain's Utility. 
Figures 1-5 show the relationship between order price, the farmer's effort level, the farmer's utility, the supermarket's utility and the supply chain's utility under different conditions when the supermarket is fair neutral or fair preference (the Nash equilibrium solution and the Shapley value is used as the fair reference point). The above verifies Conclusion 1.

As shown in Figures 3-5, neither the Nash equilibrium solution nor the Shapley value used as the fair reference point of the supermarket can achieve supply chain coordination, but the supply chain can be improved with the Shapley value as the fair reference point. The above verifies Conclusion 2 .

As can be seen from Figures 1-3 and Figure 5, when the supermarket uses the Nash equilibrium solution as the fair reference point, with the increase of the supermarket's fair preference intensity, the supermarket's order price decreases, the farmer's effort level decreases, and the utility of the farmer and supply chain decreases. It can be seen from Figure 4 that when $0<\lambda_{r}<\sqrt{3}-1$, the supermarket's utility increases with the increase of its own fair preference intensity; when $\sqrt{3}-1 \leq \lambda_{r}<1$, supermarket utility decreases with the increase of its own fair preference intensity. Figures 1-5 show that when the supermarket uses the Shapley as the fair reference point, with the increase of supermarket's fair preference intensity, the supermarket order price decreases, the farmer's effort level decreases, the farmer's utility decreases, while the supermarket's utility and the supply chain's utility increase. The above verifies Conclusion 3.

As shown in Figures 3-5, when the supermarket uses the Shapley value as the fair reference point, the utility of the farmer, the supermarket and the supply chain are relatively higher. Therefore, it is verified Conclusion 4 that when the supermarket has fair preference behavior, the farmer, the supermarket and the supply chain tend to use the Shapley value as the fair reference point.

\section{Conclusions}

In a two-echelon "Farmer-Supermarket Direct-Purchase" supply chain composed of a supermarket and a farmer, the dominant supermarket used the Nash equilibrium solution and the Shapley value as the fair reference points. By constructing the Stackelberg game model, this paper analyzed the influence of supermarket's fairness preference on the operation of supply chains and made a sensitivity analysis. The research shows that: 1) The supermarket's fairness preference decreases order prices and the effort level of farmer, increases the utility of the supermarket but reduces the income of farmer; 2) No matter whether the Nash equilibrium solution or the Shapley value is used as the fair reference point of the supermarket, the supply chain cannot be achieved coordination. However, the supply chain can be improved with the Shapley value as the fair reference point; 3) the farmer, the supermarket and the supply chain tend to use Shapley value as a fairness reference point for the supermarket.

Therefore, the following management enlightenments and policy recommendations are drawn: firstly, the stronger the fairness preference of the supermar- 
ket is, the more unfavorable it is to farmers. Therefore, the management risk can be reduced through the whole supervision of agricultural product quality by supermarkets, and the government and relevant departments can act as a third-party platform to shorten the repayment cycle, so as to reduce the unfairness of supermarkets. Secondly, because the supermarket extremely depresses the order price of agricultural products, which will lead to the continuous reduction of the farmer's efforts, the quality of agricultural products will be frequent. Therefore, the supermarket can sign a protection price purchase contract with the farmer in advance, which restricts the supermarket from lowering the order price of agricultural products regardless of consequences in order to pursue their own profits. Thirdly, because the supermarket with fairness preference occupies an absolutely dominant position, which leads to neglect of the efforts and contributions of farmers. It is possible to improve the farmer's status by means of farmer-supermarket alliance or developing a new channel.

This research also has the following shortcomings: 1) This paper is based on the premise of information symmetry, but because the farmer is in a disadvantaged position in reality, it is impossible to fully understand the fair reference point of the supermarket. The next step should consider information asymmetry. 2) This research only considers the fairness preference of the supermarket, and can further introduce the fairness behavior of the farmer at the same time to study its impact on decision-making and supply chain coordination.

\section{Acknowledgements}

The research is supported by Graduate Innovation Project of Chongqing University of Technology "Optimal Decision of Different Fairness Reference Points in Supply Chain Under 'Farmer-Supermarket Direct-Purchase' Mode” under Grant Number ycx2018267.

\section{Conflicts of Interest}

The authors declare no conflicts of interest regarding the publication of this paper.

\section{References}

[1] Hernández, R., Reardon, T. and Berdegué, J. (2010) Supermarkets, Wholesalers, and Tomato Growers in Guatemala. Agricultural Economics, 36, 281-290. https://doi.org/10.1111/j.1574-0862.2007.00206.x

[2] Jack, L., Florez-Lopez, R. and Ramon-Jeronimo, J.M. (2018) Accounting, Performance Measurement and Fairness in UK Fresh Produce Supply Networks. Accounting, Organizations and Society, 64, 17-30. https://doi.org/10.1016/j.aos.2017.12.005

[3] Yang, Y. (2017) Discussion on the Mode and Strategy of "Agricultural-Super Docking”. Journal of Commercial Economics, No. 15, 115-117.

[4] Cui, T.H., Raju, J.S. and Zhang, Z.J. (2007) Fairness and Channel Coordination. Management Science, 53, 1303-1314. https://doi.org/10.1287/mnsc.1060.0697 
[5] Katok, E., Olsen, T. and Pavlov, V. (2014) Wholesale Pricing under Mild and Privately Known Concerns for Fairness. Production \& Operations Management, 23, 285-302. https://doi.org/10.1111/j.1937-5956.2012.01388.x

[6] Qin, Y., Wei, G. and Dong, J.X. (2017) The Signaling Game Model under Asymmetric Fairness-Concern Information. Cluster Computing, No. 8, 1-16. https://doi.org/10.1007/s10586-017-1365-7

[7] Caliskan-Demirag, O., Chen, Y. and Li, J. (2010) Channel Coordination under Fairness Concerns and Nonlinear Demand. European Journal of Operational Research, 207, 1321-1326. https://doi.org/10.1016/j.ejor.2010.07.017

[8] Pu, X.J., Zhu, Q.Y. and Cao, W.B. (2014) Impact of Suppliers' Fairness Preference on Price Equilibrium in the Retailer Dominated Supply Chain. Journal of Systems \& Management, No. 6, 876-882.

[9] Du, S., Nie, T., Chu, C., et al. (2014) Newsvendor Model for a Dyadic Supply Chain with Nash Bargaining Fairness Concerns. International Journal of Production Research, 52, 5070-5085. https://doi.org/10.1080/00207543.2014.895446

[10] Zhu, L.L., Shi, Y.C., Zhu, J.A., et al. (2015) Supply Chain Optimization Based on Shapley Fair Theory. Journal of University of Science and Technology of China, No. 6, 497-506.

[11] Kurz, S., Maaser, N. and Napel, S. (2016) Fair Representation and a Linear Shapley Rule. Social Science Electronic Publishing, Chicago. https://doi.org/10.2139/ssrn.2853993

[12] Pu, X.J., Zhu, Q.Y. and Lu, L. (2016) Reference Point Effect, Fairness Preference and the Relational Governance on the Supply Chain of "Leading Agricultural Enterprises + Farmers". Journal of Industrial Engineering and Engineering Management, No. 2, 116-123.

[13] Yao, G.X. and Pu, L.B. (2014) Research on Quality Improvement and Fairness Preference Based on "Agricultural-Super Docking” Model. Commercial Research, No. $5,172-176$.

[14] Sun, Y., Liu, Z. and Yang, H. (2018) How Does Suppliers' Fairness Affect the Relationship Quality of Agricultural Product Supply Chains? Journal of Food Quality, 2018, Article ID: 9313068. https://doi.org/10.1155/2018/9313068

[15] Feng, C., Yu, B., Wang, Y.T., et al. (2018) Fair Distribution Mechanism of Channel Profit under Exponential Demand in Agri-Food Supply Chain. Journal of Systems \& Management, No. 3, 470-477.

[16] Zhang, X. and Zhang, Q. (2017) Coordination of Fresh Agricultural Supply Chain Considering Fairness Concerns under Controlling the Loss by Freshness-Keeping. Chinese Journal of Systems Science, No. 3, 112-116.

[17] Pu, X.J., Zhu, Q.Y. and Cao, W.B. (2014) Research on the Bilateral Effort of Supply Chains of Supplier Dominating in the Inspective of Fairness Preferences. Forecasting, No. 1, 56-60. 